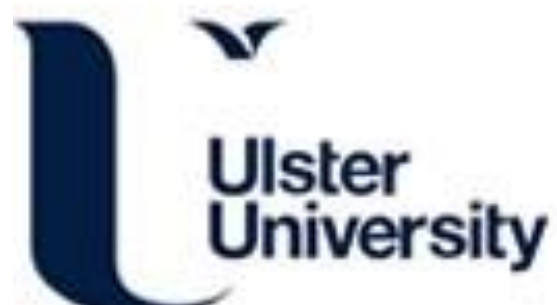

\section{Adapting Resistive Sensors for Monitoring Moisture in Smart Wound Dressings}

Cundell, J., Davis, J., Cameron, S., \& Mathur, A. (2020). Adapting Resistive Sensors for Monitoring Moisture in Smart Wound Dressings. Current Opinion in Electrochemistry, 23, 31-35.

https://doi.org/10.1016/j.coelec.2020.02.017

Link to publication record in Ulster University Research Portal

\section{Published in:}

Current Opinion in Electrochemistry

Publication Status:

Published (in print/issue): 31/10/2020

DOI:

10.1016/j.coelec.2020.02.017

\section{Document Version}

Publisher's PDF, also known as Version of record

\section{General rights}

Copyright for the publications made accessible via Ulster University's Research Portal is retained by the author(s) and / or other copyright owners and it is a condition of accessing these publications that users recognise and abide by the legal requirements associated with these rights.

\section{Take down policy}

The Research Portal is Ulster University's institutional repository that provides access to Ulster's research outputs. Every effort has been made to ensure that content in the Research Portal does not infringe any person's rights, or applicable UK laws. If you discover content in the Research Portal that you believe breaches copyright or violates any law, please contact pure-support@ulster.ac.uk. 


\section{Adapting resistive sensors for monitoring moisture in smart wound dressings Cameron Scott ${ }^{1}$, Sarah Cameron ${ }^{1}$, Jill Cundell ${ }^{2}$, Ashish Mathur ${ }^{3}$ and James Davis ${ }^{1}$}

\begin{abstract}
Moisture plays a critical role in the wound healing process and, given the multitude of electrochemical sensors aimed at measuring humidity, it is somewhat surprising that there are few systems dedicated to this particular application. The issues relating to wound moisture and the practical challenges facing the adaptation of generic resistive moisture sensors to this area are considered along with the potential impact such systems could have on nursing practice.

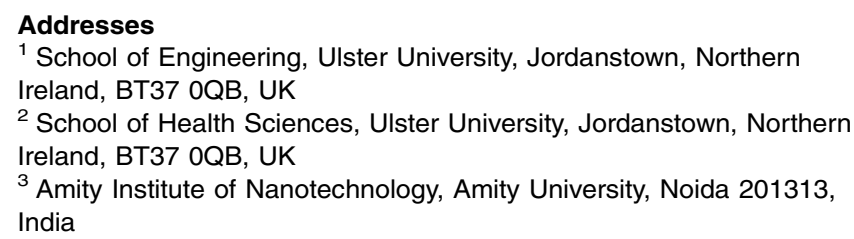

${ }^{2}$ School of Health Sciences, Ulster University, Jordanstown, Northern Ireland, BT37 0QB, UK

${ }^{3}$ Amity Institute of Nanotechnology, Amity University, Noida 201313, India

Corresponding author: Davis, James (james.davis@ulster.ac.uk)

Current Opinion in Electrochemistry 2020, 23:31-35
This review comes from a themed issue on Sensors and Biosensors
Edited by Zbigniew Stojek
For a complete overview see the Issue and the Editorial
Available online 27 February 2020
https://doi.org/10.1016/j.coelec.2020.02.017
2451-9103/@ 2020 Elsevier B.V. All rights reserved.

\section{Keywords}

Moisture, Resistive sensor, Relative humidity, Wound dressing, Smart bandages.

\section{Introduction}

Most slow healing (chronic) wounds are managed in the community by district nursing/primary care practice nurses and recent estimates by Guest et al. (2015) indicate that of 2.2 million wounds treated annually by the UK NHS, 1.45 million are managed by community nurses [1]. Maybin et al. [2] also highlight the changing patterns in community nursing, where increased numbers of patients, and the complexity of the care required, places considerable stress on existing healthcare systems. Given the likely increases in demand, it has been suggested that expenditure on healthcare services will fail to keep pace, and more fundamental changes will be required in the manner in which wound care is delivered $[2,3]$. The changing community care landscape offers considerable opportunities for the development of point-of-care devices and connected health systems that offer detailed telemetry of the patient's condition. The ideal embodiment of such a system is summarised in Figure 1 and it is possible to envisage that the provision of sensors that can acquire detailed information on a spectrum of wound biomarkers could, in principle, dramatically aid clinical decision making and improve patient outcomes.

Understanding the significance of the various biochemical players, the nuances associated with changes in their concentrations and the corresponding impact on cellular regeneration however are, much like the technologies required to monitor them, at very early stages of development. As such, few systems have been able to reach commercial maturity and, in most cases, the development cycle tends to become entangled at the proof-of-concept stage, and there are a number of reviews on emerging and future developments within the field [4-6]. Yet, it could be argued that the sensing technologies required to make substantive differences to wound management in the present, already exist. Monitoring simple parameters such as moisture associated with the wound fluid have long been recognised as key parameters in the day to day management of complex wounds.

The aim of this perspective has been to provide some critical insights into the translation of resistive sensor technologies for monitoring moisture levels (particularly relative humidity, RH) within conventional wound dressings. Rather than providing an exhaustive examination of RH sensors, the focus is on highlighting some recent developments and their applicability to the particular requirements of wound diagnostics and potential value to decentralised community wound management.

\section{The significance of moisture in wound care}

The provision of a moist wound environment has been a key tenet of wound care since the seminal papers of Winter in the 1960s [7-10] and is often regarded as the single most significant advance in wound care in recent 
Figure 1

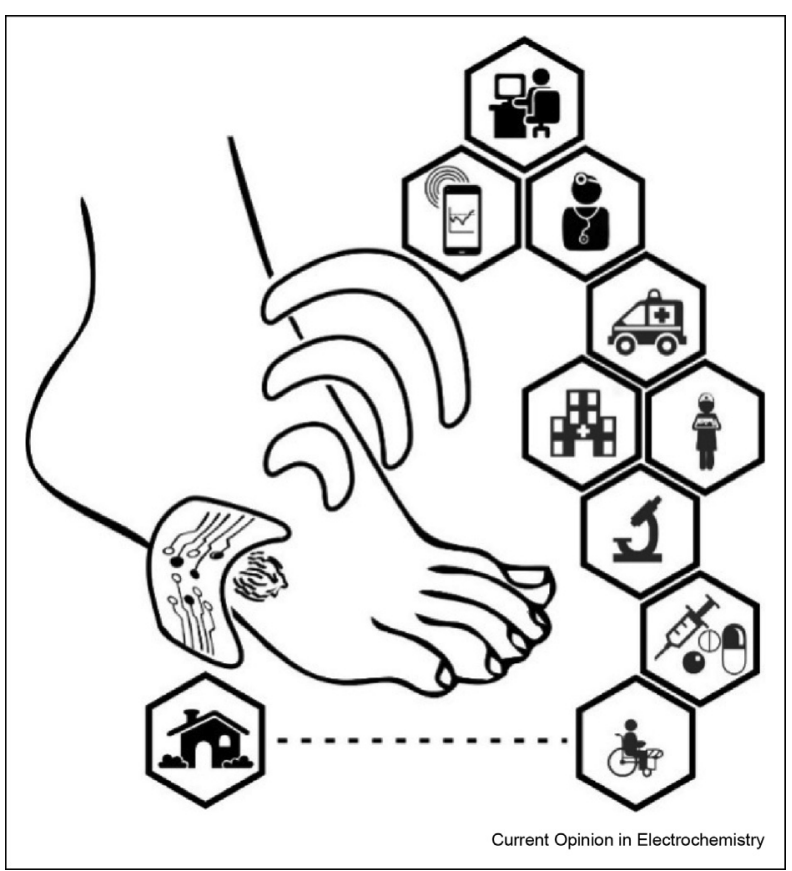

Idealised smart wound dressing enabling telemetry of the wound environment that can aid healing and provide proactive monitoring of complications and infection.

decades. Maintaining an adequate level of hydration within the wound bed has been shown to be critical to facilitating the operation of the biochemical reactions that are responsible for triggering the granulation and reepithelialisation processes that expediate wound healing. In contrast, the presence of too much fluid at the wound site can dramatically hinder the healing processes and induce further clinical complications [11]. Moisture-associated skin damage can result as a consequence of numerous factors (physical, chemical and microbial) acting in concert or individually. In chronic wounds, moisture-associated skin damage can be exacerbated simply through prolonged contact with wound exudate. Protein degrading enzymes (serine protease, elastase and metalloproteases), neutrophils and proinflammatory cytokines are typically present at high concentrations within wound exudate and can be considered to be a 'wounding agent' in its own right when left in contact with peri wound skin for excessive periods [11,12]. Rather than aiding closure of the wound, excess exudates can result in wound enlargement. The stalling of wound healing inevitably leads to an increased risk of infection with limb and life-threatening consequences.

\section{Sensors for moisture measurement}

Extensive research has been carried out into humidity/ moisture based sensors for a wide range of agrifood, environmental, commercial and industrial applications but the translation of such technologies to the context of wound monitoring however brings a whole new series of challenges: disposability, low cost, biocompatibility, flexibility and a capacity to be miniaturised being among the more common. Milne et al. [13] pioneered the early development of wound moisture sensors and pursued the technology through to clinical realisation with the release of their Wound sense ${ }^{\mathrm{TM}}$ device. Their system involved embedding a disposable sensing strip (composed of two silver/silver chloride electrodes) within a conventional wound dressing with ac impedance measurements used to assess the moisture content of the latter. The device relied upon the wicking of the wound moisture into the dressing enabling electrical connection between electrodes. Whilst not strictly a humidity sensor, this early design enabled a measure of dressing saturation - with data presented directly to the nurse in an accessible dashboard display indicating the condition of the dressing from dry to sodden. The system lacked the sensitivity (and reversibility) needed for dynamic profiling of moisture fluctuations within the wound and the absence of autonomous reporting necessitated a high degree of nurse involvement. A number of designs have since arisen in an attempt to address the latter with wireless transmission of the moisture data to a smart phone/app [14]. However, it is clear that there remains much to be carried out to enable the idealised system advocated in Figure 1.

A range of analytical methodologies have been investigated in the development of humidity sensors (principally RH \%) but there are several general electrochemical categories: resistive, impedance and capacitive sensors. These can be further subdivided depending on the type of the core sensing material with nano structured variants coming to dominate recent literature offering improved manufacturing processability and device sensitivity and these are the focus of the present review. The different approaches are briefly summarised in Table 1.

\section{Resistive sensors}

Resistive sensors RH sensors have a long history and, from a wound monitoring perspective, possess the advantage of requiring little in terms of supporting electronics. This is a critical point as, although much is often made of the small dimensions/flexibility of the sensor, the fact that the controlling electronics will also be in the vicinity of the wound and possibly located on the dressing or surrounding skin is often overlooked. The smaller the footprint of the controller/reporter, the less obtrusive the system and thereby minimises discomfort to the patient.

\section{Sensing materials}

Ceramic and metal oxide systems have been used extensively within industrial processes operating at 


\begin{tabular}{|c|c|c|c|c|}
\hline \multicolumn{5}{|c|}{ Materials used in resistive humidity sensors. } \\
\hline Inorganics/oxides & Flexible & $\begin{array}{l}\text { Range } \\
\% R H\end{array}$ & Sample & Reference \\
\hline $\begin{array}{l}\text { Polyimide with } \mathrm{TiO}_{2} \\
\text { nanoflowers }\end{array}$ & Y & $20-95$ & Breath & [15] \\
\hline $\mathrm{CuMn}_{2} \mathrm{O}_{4} /$ chitosan & $\mathrm{N}$ & $20-95$ & NS & [16] \\
\hline $\mathrm{Cu} / \mathrm{Cu}_{\mathrm{x}} \mathrm{O} /$ polycarbonate & $\mathrm{Y}$ & $0-55$ & Breath & [17] \\
\hline $\mathrm{ZnO} / \mathrm{MoS}_{2}$ & $\mathrm{~N}$ & $35-85$ & Air Quality & [14] \\
\hline Nanoporous $\mathrm{Nb}_{2} \mathrm{O}_{5}$ & $\mathrm{~N}$ & $40-90$ & NS & [18] \\
\hline $\mathrm{ZnFe}_{2} \mathrm{O}_{4}$ spinel & $\mathrm{N}$ & $30-90$ & NS & [19] \\
\hline $\begin{array}{l}\mathrm{NiPS}_{3} 2 \mathrm{D} \text { material on } \\
\text { polypropylene }\end{array}$ & Y & $11-97$ & Breath & [20] \\
\hline \multicolumn{5}{|c|}{ Polymers/carbon nanomaterials } \\
\hline PEDOT/PSS/Paper & $\mathrm{Y}$ & $10-90$ & Artworks & {$[21]$} \\
\hline $\begin{array}{l}\text { Polyelectrolyte PMDS/ } \\
\text { PPDS }\end{array}$ & $\mathrm{N}$ & $10-95$ & Breath & [22] \\
\hline PEDOT/PSS/GO/PET & Y & $0-100$ & Air & [23] \\
\hline $\begin{array}{l}\text { MWCNT/ } \\
\text { hydroxycellulose/ } \\
\text { polyethylene } \\
\text { terephthalate (PET) }\end{array}$ & $\mathrm{Y}$ & $20-80$ & NS & [24] \\
\hline MWCNT/cellulose/PAA & $\mathrm{Y}$ & $30-95$ & Sweat & [25] \\
\hline Gelatin GO & $\mathrm{Y}$ & $0-95$ & NS & [26] \\
\hline $\begin{array}{l}\text { MWCNT/soybean oil } \\
\text { and poly (ethylene } \\
\text { glycol) methyl ether } \\
\text { acrylate }\end{array}$ & Y & $6-84$ & NS & {$[27]$} \\
\hline MWCNT/Chitosan & $\mathrm{N}$ & $30-100$ & NS & [28] \\
\hline
\end{tabular}

$\mathrm{GO}=$ Graphene oxide; MWCNT $=$ Multiwalled carbon nanotube; PAA = Polyacrylic Acid; PET = Poly; PEDOT = poly(3,4-ethylenedioxythiophene); PSS = poly(styrene sulphonate); PMDS = poly(mercaptopropyl polyhedral oligomeric silsesquioxane-1,4-divinylbenzene-sodium $p$-styrene sulfonate hydrate); PPDS = poly(pentaerythritol tetra(3-mercaptopropionate)-1,4divinylbenzene-sodium $p$-styrene sulfonate hydrate); $P E T$ = polyethylene terephthalate; NS $=$ Not specified.

higher temperatures but have historically been known to be less responsive at low $\% \mathrm{RH}-$ especially at the low temperatures expected within the wound environment. A variety of nano particle/nano oxide systems (Table 1), many incorporated into composite formulations, have sought to address some of these issues where the increased surface area and porosity of the materials aim to improve sensitivity.

Work by Jeong et al. [15] is particularly pertinent to the present discussion as they have successfully developed an inexpensive continuous roll-to-roll (R2R) polyimide print system in which nano-sculptured $\mathrm{TiO}_{2}$ flowers are immobilised on silver interdigitated electrodes. The latter have been shown to be sensitive to moisture over a wide \% RH range $(20-95 \%)$ and possess the reversibility needed for dynamic measurements. Similarly, Hassan et al. [23] have developed an inkjet fabrication process on a flexible PET substrate but instead of a single sensor attempting to cover the entire RH range, they have adopted a three sensor configuration with each targeting a different $\mathrm{RH}$ region. It is easy to envisage both print processes providing ease of manufacture and at the volume required for disposable wound diagnostics but it could be argued that the 3-sensor system, whereas embracing a high degree of accuracy, is over-engineered for the problem at hand.

The response mechanism for many of the oxide systems is based on the chemisorption of water molecules onto the hydrophilic surface of the nanoparticles. At low RH, the former dissociate yielding hydroxyl groups adsorbed to the metal particle and mobile protons, resulting in high-charge carrier densities and hence larger current. As the RH is increased, multiple layers of water accumulate and form continuous dipoles and electrolyte layers between the connecting electrodes providing bulk conductivity. As the RH increases towards $100 \%$, it can be fair to assume that the dressing is becoming saturated with moisture and, at that point (while perhaps not sodden) would signal a need for replacement.

Although the resistance of the metal oxide nanoparticle systems decrease markedly with increasing RH [15], the reverse is true in the case of many systems that exploit polymer composites encapsulating carbon nanomaterials (typically nanotube, graphene/graphene oxide). As the $\mathrm{RH}$ is increased, the polymeric binder swells, increasing the separation between the carbon materials (decreasing intertube/particle connection and percolation) and thereby increases the resistance. A critical element here is the need to have hydrophilic components that can readily facilitate the swelling process otherwise the resistance changes (and hence sensitivity) at low RH can be small. This has been countered by the use of hydroxycellulose [24], polyacrylic acid [25], various acrylated esters [27] and chitosan [28] all of which provide hydrophilic functionalities that induce significant volume changes upon exposure to low moisture levels.

\section{Practicalities of the designs}

Wounds will exhibit a wide range of morphologies and thus the ability of the sensor to conform to the contours of the damaged skin is critical. It can be seen from Table 1 that a number of sensors have utilised mechanically flexible substrates (driven in part by the increasing interest in wearable systems). Nevertheless, the work by Jeong et al. [15] is again significant in that repeated deformation of the polyimide substrate did not lead to any significant deterioration of the sensor response and could be particularly useful where the patient is ambulatory and the wound site liable to a degree of motion and distortion.

In most cases, interdigitated electrodes (typically, Au, $\mathrm{Ag}$ or $\mathrm{Pt}$ ) have been used as the connecting electrodes, it 
could be anticipated that the use of laser-induced graphene to scribe the circuit connections [29,30] could yield further improvements in the manufacturing process (potentially reducing cost per sensor and increasing adaptability of sensor deign), and it is notable that such systems have increased across the sensing communities in recent years.

Biocompatibility will always be an issue and, although there can be suspicion over the use of some of the systems highlighted in Table 1, it is important to note that the sensors are embedded within the dressing and are unlikely to be in direct contact with the wound itself. Moreover, to ensure adequate adherence to a flexible substrate, protective films are invariably used to encapsulate the components (often with the cointention of aiding the adsorption of water) and thus effectively removed from interaction with the wound tissue.

\section{Potential impact on practice}

The provision of simple moisture sensing systems that can perform such duties autonomously could yield significant benefits in terms of optimising hard pressed community resources through the prioritisation of nurse visits. A study by Milne et al. [13] found that more than $40 \%$ of dressings were changed prematurely. It is generally accepted that the bulk of the costs associated with wound management is attributed not to the dressings and associated devices but rather to staff time and that the resources consumed in managing wounds in the community typically require $20 \%$ more visits to practice nurse visits and an increase of $104 \%$ community nurse visits to the patient [31]. Improved access to information technology (and hence sensor telemetry), enabling specialist input from remote consultations and greater educational support, have been cited as prioritising referrals and reducing unnecessary visits [32].

\section{Conclusions}

Despite many advances in materials and procedures, it must be recognised that, once applied, both conventional and 'advanced' dressings are essentially blind and an evaluation of their effectiveness in manipulating the wound environment remains subject to visual inspection by the attending healthcare professional only upon removal. The ability to monitor the moisture content and also detect when dressings need to be changed could be a critical addition to the community nursing tools.

\section{Conflict of interest statement}

Nothing declared.

\section{Acknowledgements}

The authors are pleased to acknowledge financial support from the Department for the Economy (DfE) Northern Ireland and the British Council UKIERI (DST 65/2017).

\section{References}

Papers of particular interest, published within the period of review, have been highlighted as:

* of special interest

** of outstanding interest

1. Guest JF, Ayoub N, Mcllwraith T, Uchegbu I, Gerrish A, Weidlich D, Vowden K, Vowden P: Health economic burden that wounds impose on the National Health Service in the UK BMJ Open 2015, 5:1-8, https://doi.org/10.1136/bmjopen-2015009283.

2. Maybin J, Charles A, Honeyman M: The Kings Fund. Understanding quality in district nursing servicesLearning from patients, carers and staff. 2016. https://www.kingsfund.org.uk/sites/default/ files/field/field_publication_file/quality_district_nursing_aug_2016. pdf.

3. Dowsett C, Bielby A, Searle R: Reconciling increasing wound care demands with available resources. J Wound Care 2014, 23:552-562, https://doi.org/10.12968/ jowc.2014.23.11.552.

4. McLister A, Phair J, Cundell J, Davis J: Electrochemical approaches to the development of smart bandages: a minireview. Electrochem Commun 2014, 40, https://doi.org/10.1016/ j.elecom.2014.01.003.

5. Mehmood N, Hariz A, Fitridge R, Voelcker NH: Applications of modern sensors and wireless technology in effective wound management. J Biomed Mater Res B Appl Biomater 2014, 102: 885-895, https://doi.org/10.1002/jbm.b.33063.

6. Dargaville TR, Farrugia BL, Broadbent JA, Pace S, Upton Z, Voelcker $\mathrm{NH}$ : Sensors and imaging for wound healing: a review. Biosens Bioelectron 2013, 41:30-42, https://doi.org/ 10.1016/j.bios.2012.09.029.

7. Winter GD: Ormation of the scab and the rate of epithelization of superficial wounds in the skin of the young domestic pig. Nature 1962, 193:293-294.

8. Winter GD: Effect of air exposure and occlusion on experimental human skin wounds. Nature 1963, 200:378-379.

9. Winter GD: A note on wound healing under dressings with special reference to perforated-film dressings. J Invest Dermatol 1965, 45:299-302.

10. Winter GD: Effect of air drying and dressings on the surface of the wound. Nature 1963, 197:91-92.

11. Cutting KF, White RJ: Maceration of the skin and wound bed. 1: its nature and causes. J Wound Care 2002, 11:275-278, https://doi.org/10.12968/jowc.2002.11.7.26414.

12. Trengove NJ, Langton SR, Stacey MC: Biochemical analysis of wound fluid from nonhealing and healing chronic leg ulcers. Wound Repair Regen 1996, 4:234-239.

13. Milne SD, Seoudi I, AI Hamad H, Talal TK, Anoop AA, Allahverdi N, Zakaria Z, Menzies R, Connolly P: A wearable wound moisture sensor as an indicator for wound dressing change: an observational study of wound moisture and status. Int Wound J 2016, 13:1309-1314, https://doi.org/ 10.1111/iwj.12521.

First clinical study of a moisture sensor in practice and its potential impact on nursing prioritisation.

14. Burman D, Choudhary DS, Guha PK: ZnO/MoS2-Based enhanced humidity sensor prototype with android app interface for mobile platform. IEEE Sensor J 2019, 19: 3993-3999, https://doi.org/10.1109/JSEN.2019.2896208. Fully fledged prototype offering wireless connectivity and smart app dashboard for a disposable moisture sensor.

15. Jeong $H$, Noh $Y$, Lee D: Highly stable and sensitive resistive flexible humidity sensors by means of roll-to-roll printed electrodes and flower-like TiO2 nanostructures. Ceram Int 2019, 45:985-992, https://doi.org/10.1016/ j.ceramint.2018.09.276.

Versatile resistive sensor platform offering characteristics compatible with the demands of wound moisture sensing. 
16. Chani MTS, Karimov KS, Khan SB, Fatima N, Asiri AM: Impedimetric humidity and temperature sensing properties of chitosan-CuMn 204 spinel nanocomposite. Ceram Int 2019 , 45:10565-10571, https://doi.org/10.1016/j.ceramint.2019.02.122.

17. Zhou X, Guo W, Fu J, Zhu Y, Huang Y, Peng P: Laser writing of $\mathrm{Cu} / \mathrm{CuxO}$ integrated structure on flexible substrate for humidity sensing. Appl Surf Sci 2019, 494:684-690, https:// doi.org/10.1016/j.apsusc.2019.07.159.

18. Abdul Rani R, Zoolfakar AS, Mohamad Ryeeshyam MF, Ismail AS, Mamat MH, Alrokayan S, Khan H, Kalantar-zadeh K, Mahmood MR: High surface area to volume ratio 3D nanoporous $\mathrm{Nb2O5}$ for enhanced humidity sensing. J Electron Mater 2019, 48:3805-3815, https://doi.org/10.1007/s11664-01907126-5.

19. Nikolic MV, Vasiljevic ZZ, Lukovic MD, Pavlovic VP, Krstic JB, Vujancevic J, Tadic N, Vlahovic B, Pavlovic VB: Investigation of $\mathrm{ZnFe} 204$ spinel ferrite nanocrystalline screen-printed thick films for application in humidity sensing. Int J Appl Ceram Technol 2019, 16:981-993, https://doi.org/10.1111/ijac.13190.

20. Jenjeti RN, Kumar R, Sampath S: Two-dimensional, few-layer NiPS3 for flexible humidity sensor with high selectivity. J Mater Chem 2019, 7:14545-14551, https://doi.org/10.1039/ c9ta03214b.

21. Zhang $Y$, Cui $Y$ : A flexible calligraphy-integrated in situ humidity sensor, Measurement. J Int Meas Confed 2019, 147: 106853, https://doi.org/10.1016/j.measurement.2019.106853.

22. Dai J, Zhao H, Lin X, Liu S, Liu Y, Liu X, Fei T, Zhang T: Ultrafast response polyelectrolyte humidity sensor for respiration monitoring. ACS Appl Mater Interfaces 2019, 11:6483-6490, https://doi.org/10.1021/acsami.8b18904.

Rapid response/reversibility for non contact moisture sensing which could be particularly suitable for integration within wound dressings

23. Hassan G, Sajid M, Choi C: Highly sensitive and full range detectable humidity sensor using PEDOT:PSS, methyl red and graphene oxide materials. Sci Rep 2019, 9:1, https:// doi.org/10.1038/s41598-019-51712-w.

Inkjet printable sensor with full range sensitivity on a flexible substrate compatible with variable demands of wound morphology

24. Turkani VS, Maddipatla D, Narakathu BB, Saeed TS, Obare SO Bazuin BJ, Atashbar MZ: A highly sensitive printed humidity sensor based on a functionalized MWCNT/HEC composite for flexible electronics application. Nanoscale Adv 2019, 1: 2311-2322, https://doi.org/10.1039/c9na00179d.

25. Zhang J, Dichiara AB, Novosselov I, Gao D, Chung JH: Polyacrylic acid coated carbon nanotube-paper composites for humidity and moisture sensing. J Mater Chem C 2019, 7: 5374-5380, https://doi.org/10.1039/c9tc01254k.

26. Nassira H, Sánchez-Ferrer A, Adamcik J, Handschin S, Mahdavi H, Taheri Qazvini N, Mezzenga R: Gelatin-graphene nanocomposites with ultralow electrical percolation threshold. Adv Mater 2016, 28:6914-6920, https://doi.org/ 10.1002/adma.201601115.

27. Ni X, Luo J, Liu R, Liu X: A novel flexible UV-cured carbon nanotube composite film for humidity sensing. Sensor Actuator B Chem 2019, 297, https://doi.org/10.1016/ j.snb.2019.126785.

28. Kim HS, Kim JH, Park SY, Kang JH, Kim SJ, Choi YB, Shin US: Carbon nanotubes immobilized on gold electrode as an electrochemical humidity sensor. Sensor Actuator B Chem 2019, 300:127049, https://doi.org/10.1016/..snb.2019.127049.

29. Romero FJ, Rivadeneyra A, Salinas-Castillo A, Ohata A Morales DP, Becherer M, Rodriguez N: Design, fabrication and characterization of capacitive humidity sensors based on emerging flexible technologies. Sensor Actuator B Chem 2019 , 287:459-467, https://doi.org/10.1016/j.snb.2019.02.043.

30. Nie J, Wu Y, Huang Q, Joshi N, Li N, Meng X, Zheng S, Zhang M, Mi B, Lin L: Dew point measurement using a carbon-based capacitive sensor with active temperature control. ACS Appl Mater Interfaces 2019, 11:1699-1705, https://doi.org/10.1021/ acsami.8b18538.

LIG based sensor design that could be a competitive alternative to printed interdigitated electrodes for ad hoc investigation or online manufacturing.

31. Guest JF, Ayoub N, Mcllwraith T, Uchegbu I, Gerrish A, Weidlich D, Vowden K, Vowden P: Health economic burden that different wound types impose on the UK's National Health Service. Int Wound J 2017, 14:322-330, https://doi.org/ 10.1111/iwj.12603.

32. Vimalananda VG, Gupte G, Seraj SM, Orlander J, Berlowitz D, Fincke BG, Simon SR: Electronic consultations (e-consults) to improve access to specialty care: a systematic review and narrative synthesis. J Telemed Telecare 2015, 21:323-330, https://doi.org/10.1177/1357633X15582108. 